\title{
Diagnóstico da gestão de resíduos da construção civil a partir da leitura da paisagem urbana
}

\author{
Diagnosis of civil Construction Waste Management from the reading of the \\ urban landscape
}

\author{
Renam Serraglio Quaglio ${ }^{1}$ \\ Alba Regina Azevedo Arana ${ }^{2}$
}

\section{Palavras-chave: \\ Meio ambiente \\ Risco ambiental \\ Disposição inadequada \\ Resíduos}

\begin{abstract}
Resumo
A construção civil pode ser identificada como um dos setores que mais causam impactos ao meio ambiente devido à exploração dos recursos naturais e elevado índice de geração de resíduos. Neste contexto, este estudo tem por objetivo elencar as principais áreas de descarte inadequado dos Resíduos de Construção e DemoliçãoRCD no município de Presidente Bernardes-SP apresentando suas características e análise espacial. Os procedimentos metodológicos para a caracterização das áreas foram constituídos por visitas aos pontos de descarte, efetuação de registro fotográfico, demarcação de coordenadas geográficas e observação direta da composição dos RCD. Após uma investigação detalhada do perímetro urbano e acessos do município foram demarcados 40 pontos de descarte irregular que possuíam mais de $3 \mathrm{~m}^{3}$ de RCD depositados. Á área do município foi subdividida de acordo com as feições urbanas. Em todos os pontos analisados foram identificados resíduos da Classe A, $82,5 \%$ da Classe B, 47,5\% da Classe C e D, também foi verificado que $20 \%$ dos pontos apresentavam resíduos domiciliares evidenciando o poder de atratividade dos RCD. A partir dos resultados foi possível relacionar as principais áreas de descarte irregular, bem como estimar o volume de resíduos descartados e sua composição fornecendo subsídios à implantação de uma gestão diferenciada no município.
\end{abstract}

\section{Keywords:}

Environment

Environmental risk

Inadequate provision

Waste

\begin{abstract}
Civil construction can be identified as one of the sectors that most cause impacts to the environment due to exploitation of natural resources and high rate of waste generation. In this context, this study aims to list the main areas of inappropriate disposal of RCD in the municipality of Presidente Bernardes-SP presenting its characteristics and spatial analysis. The methodological procedures for the characterization of the areas were constituted by visits to the disposal points, photographic registration,
\end{abstract}

\footnotetext{
${ }^{1}$ UNIFAI - Centro Universitário de Adamantina. Adamantina, SP, Brasil. renamserraglio@ hotmail.com

${ }^{2}$ Universidade do Oeste Paulista. Programa de Pós-Graduação em Meio Ambiente e Desenvolvimento Regional. Presidente Prudente, SP, Brasil. alba@unoeste.br
} 
geographical coordinates demarcation and direct observation of the RCD composition. After a detailed investigation of the urban perimeter and accesses of the municipality were demarcated 40 points of irregular disposal that had more than $3 \mathrm{~m}^{3}$ of deposited RCDs. The area of the municipality was subdivided according to the urban features. Class A, $82.5 \%$ of Class B, $47.5 \%$ of Class C and $\mathrm{D}$ were identified in all the analyzed points, it was also verified that $20 \%$ of the points had household residues evidencing the power attractiveness of RCDs. From the results it was possible to relate the main areas of irregular disposal, as well as to estimate the volume of waste discarded and its composition, providing subsidies to the implementation of a differentiated management in the municipality.

\section{INTRODUÇÃO}

O aumento do processo da urbanização em conjunto com o crescimento populacional das cidades tem ocasionado um crescimento das obras tanto de função habitacional como também de infraestrutura urbana. Tal ampliação influi diretamente no zoneamento urbano devido à exploração de novas áreas, afetando diretamente os ecossistemas ali existentes (SILVA; RANIERI 2014; GOUVEIA,2012). Além disto, a expansão de loteamentos é fator preocupante para o poder público de cidades que não apresentam recursos para atender de forma regular o saneamento básico necessário para as inúmeras residências que serão implantadas (GOMES et al, 2014). Os principais serviços básicos que podem sofrer deficiências com a falta de planejamento e gestão são o abastecimento de águas, esgotamento sanitário, drenagem de águas pluviais e o sistema de gerenciamento de resíduos sólidos.

Dentre esses aspectos acima, pode-se destacar a problemática ligada à gestão dos resíduos sólidos urbanos (RSU), que devido à diversidade e volume dos materiais de que são compostos afetam instantaneamente os locais de disposição, devido a essa condição devem ser descartados de forma a evitar o mínimo de impacto socioambiental. Entretanto o panorama nacional não é favorável quanto à disposição ambientalmente correta destes resíduos, segundo dados do IBGE (2012a) cerca de 50\% dos municípios brasileiros destinam seus resíduos de forma incorreta introduzindo uma série de consequências à saúde pública e ao meio ambiente.

Em meio à diversidade dos resíduos sólidos urbanos destacam-se os resíduos da construção e demolição, ou também chamados de resíduos da construção civil. Segundo a Política Nacional de
Resíduos Sólidos os resíduos da construção civil são: “[...] os gerados nas construções, reformas, reparos e demolições de obras de construção civil, incluídas os resultantes da preparação e escavação de terrenos para obras civis" (BRASIL, 2010).

Neste contexto, o presente estudo surgiu do anseio de compreender o quão impactante o descarte dos RCD vem sendo ao meio ambiente, desde a sua geração na área urbana até sua logística e destinação final. As experiências em obras da construção civil revelaram a problemática que o montante gerado composto por diversos tipos de materiais (plástico, papelão, resinas, tintas, madeiras e gesso) são dispostos em locais sem a mínima preocupação com as consequências geradas ao meio ambiente.

Nesse cenário, o artigo tem como objetivo relatar através da leitura da paisagem, os impactos ambientais causados pela disposição inadequada dos RCD no município de Presidente Bernardes - SP. Pois, os impactos oriundos da deposição irregular de RCD configuram-se como um dos dilemas enfrentados pelo poder público, tanto pela ausência de áreas para a correta destinação, como pelo gerenciamento adequado que demanda elevados investimentos.

Desta forma, o trabalho traz como questionamento: Quais os principais impactos ambientais ocasionados pelo descarte inadequado dos RCD no município? Qual a relação do RCD com a tipologia de área de disposição no município?

$\mathrm{O}$ artigo primeiro traz uma discussão sobre a urbanização, paisagens e feições urbanas, no segundo tópico são tratados os impactos dos resíduos da construção e demolição. A seguir o processo metodológico utilizado para execução da pesquisa de campo e a descrição do objeto de estudo. Logo a depois, os resultados da pesquisa juntamente com a discussão, apresentando o 
contexto as feições urbanas e pontos de descarte dos RCD em Presidente Bernardes - SP.

\section{URBANIZAÇÃO: PAISAGEM E FEIÇÕES URBANAS}

Guimarães (2016) enfatiza que o processo de urbanização no Brasil produziu uma série de distorções e desequilíbrios que se manifestaram empiricamente de variadas formas, sendo um gerador de exclusão e re-inclusão que ocasiona desequilíbrios regionais, urbano-rurais e urbanourbanos.

As cidades apresentam diferentes configurações espaciais, cada uma delas inseridas em contextos socioespaciais específicos, nos quais a presença ou ausência de certas características dão similaridades e singularidade a cada uma. Compreendê-las, perpassam pelo processo de produção do espaço urbano e de sua urbanização (SILVA; SPOSITO, 2017).

A morfologia urbana possui forte relação com o estudo da paisagem urbana e possibilitaria que se qualificasse e que se comparasse a paisagem da cidade. Para Carlos (2004) paisagem permitiria a apreensão do visível-sensível, tanto quanto o qualificaria como produto social, como manifestação formal da ação do Homem. Para Santos (2006) o espaço é algo que abriga a configuração geográfica ou sua configuração espacial e a maneira como esses objetos se dão, isto é a paisagem.

Sposito (2011, p.137), destaca a necessidade de revalorizar o conceito de morfologia urbana no "sentido da articulação entre as formas, os processos e as lógicas que ensejam as dinâmicas de estruturação" e enfoca a relação entre situação geográfica e morfologia urbana.

A forma urbana e as ações do homem no território estão ligadas ao espaço urbano dotado de uma história produzida por atores sociais e sujeitos coletivos, que projetam e o modelam. A cidade cria seus signos construindo uma linguagem própria de acordo com seus habitantes, agregando valores que atraem capitais e formação de redes urbanas, tudo que se cria é vendido, tornando o espaço dinâmico como se a cidade por si só tivesse vida própria (LEFEBVRE, 2008; 2016).

Panerai (2013) afirma que: o tecido urbano, que é a sobreposição de várias estruturas agindo em diferentes níveis, mas que parece ser um sistema articulado com cada parte da cidade.

Já para Fernandes (2008, p.330), “a organização da cidade actual pressupõe a consideração de factores políticos, económicos, sociais, culturais e tecnológicos de hoje", em diferentes contextos temporais e espaciais.

Diante desse cenário, é evidente que a urbanização que está diretamente relacionado ao crescimento econômico social da população, levou ao crescimento do setor da construção civil.

\section{IMPACTOS DOS RESÍDUOS CONSTRUÇÃO E DEMOLIÇÃO}

A construção civil é um segmento importante da indústria brasileira e encontra-se diretamente ligada ao desenvolvimento social e econômico do país. A importância do setor se dá pela proporção do valor adicionado das atividades e pelo efeito multiplicador de renda e sua interdependência estrutural (TEIXEIRA, 2010).

Os Resíduos da Construção e Demolição (RCD) também denominados de resíduos da construção civil (RCC) ou simplesmente "entulho", estes são provenientes de construções, reformas, reparos e demolições de obras de construção civil, e os resultantes da preparação e escavação de terrenos, tais como: tijolos, blocos cerâmicos, concreto em geral, solos, rochas, metais, resinas, colas, tintas, madeiras e compensados, forros, argamassa, gesso, telhas, pavimento asfáltico, vidros, plásticos, tubulações e fiação elétrica (CONAMA, 2002).

Os RCD são gerados em todas as etapas construtivas de uma obra, desde os serviços de terraplanagem até a limpeza final da obra. Silva e Fernandes (2012) e Malia, Brito e Bravo (2011) consideram que esses resíduos são gerados basicamente de três formas: novas construções, reformas e demolições. As perdas em grande escala do setor da construção civil são ocasionadas principalmente devido ao desperdício de materiais nas construções (ZORDAN, 2002).

No caso dos resíduos sólidos, a PNRS,Lei ${ }^{\circ}$ 12.305/2010 (BRASIL, 2010) define a gestão integrada como um conjunto de medidas voltadas para a construção de soluções para o manejo dos resíduos sólidos, de forma a considerar as dimensões econômicas, políticas, ambientais, culturais e sociais, sob os princípios do desenvolvimento sustentável e o seu gerenciamento como um conjunto de ações exercidas, direta ou indiretamente, nas etapas de coleta, transporte, transbordo, tratamento e destinação final dos resíduos sólidos e disposição final dos rejeitos, considerando que a destinação e disposição são ambientalmente adequadas, de acordo com os planos municipais de gestão 
integrada e de gerenciamento de resíduos sólidos (MARTINS, 2012).

As discussões das questões ambientais que envolvem os RCD estão intimamente ligadas com o desperdício dos recursos naturais e a escassez de locais de deposição de resíduos. A disposição inadequada dos resíduos, além de ocasionar transtorno à população, demanda de vultosos investimentos financeiros, o que coloca a indústria da construção civil o centro de discussões na busca de pelo desenvolvimento sustentável nas suas diversas dimensões (TANG et al., 2020).

De acordo com Gomes et al. (2019), a geração dos Resíduos de Construção e Demolição-RCD em cidades brasileiras de grande e médio porte corresponde aproximadamente a 41 a $71 \%$ da massa dos resíduos sólidos urbanos. Segundo Sanches (2004) quantidade de RCD gerada no Brasil gira em torno de 400 a $500 \mathrm{~kg} / \mathrm{hab}$./ano e esta produção esta ligada diretamente à cultura construtiva.

Mesmo com os instrumentos legais reguladores da gestão dos RCD verifica-se o surgimento de inúmeras áreas de disposição irregular ou clandestina, com isso grande parte do RCD produzido pelos centros urbanos é descartado em áreas públicas ou privadas nomeadas por alguns autores como "bota-foras clandestinos".

De acordo com Catunda Pinto, Santos e Catunda (2015), são várias as consequências negativas causadas pelo fluxo irracional e descontrolado do grande volume de RCD gerado nos municípios.

Esses consequências são identificadas no momento que os RCD são gerenciados e dispostos de maneira incorreta, visto que são destinados a terminar sua vida útil sendo despejado a céu aberto em aterros sanitários, causando danos ambientais como degradação e poluição do solo e corpos d'água e mananciais, bloqueio do sistema de drenagem urbano, crescimento de enchentes, proliferação de doenças, degradação da paisagem urbana e outros vetores de degradação urbana (KLEIN; GONÇALVES-DIAS, 2017).

Para Barros e Souza (2017) o impacto ambiental causado pela má gestão dos RCD não são pequenos nem simples, a inexistência de políticas públicas que disciplinem a destinação dos resíduos e tudo isso associado a um ineficaz gerenciamento ambiental de alguns agentes ligados à gestão dos RCD, impõe-se à a necessidade de uma gestão correta dos resíduos sólidos da construção civil.

Segundo Albuquerque (2015) outro fator agravante da disposição inadequada dos RCD é que estes são lançados majoritariamente em áreas de preservação permanente (APP), ou seja, áreas de grande importância pela função ambiental.

A redução da geração de resíduos na fonte é a principal ação que o poder público deve implementar. Desta forma, a destinação correta para os RCD deve ser baseada no tripé da redução, reutilização e reciclagem, fatores fundamentais para diminuir a grande massa produzida. O montante que não for reaproveitado deve seguir para o Aterro de Resíduos de Construção Civil devidamente licenciado junto aos órgãos ambientais conforme indicado na Resolução 307 do CONAMA e normalizado pela ABNT na NBR 15.113/2004.

\section{MÉTODO}

As bases metodológicas foram norteadas por estudos e publicações sobre as características dos RCD e sua gestão, os principais autores adotados foram Marques Neto (2005), Fonseca (2008) e Albuquerque (2015)

A pesquisa documental foi realizada junto a prefeitura de Presidente Bernardes com o objetivo de colher informações sobre os pontos de disposição irregular de RCD. As ruas do município foram percorridas com uma motocicleta marca Honda, modelo "NXR 150 Bross" a fim de se verificar todos os pontos de descarte existentes nas datas do levantamento.

Os procedimentos foram constituídos por visitas aos pontos de descarte, efetuação de registro fotográfico, demarcação de coordenadas geográficas, observação direta da composição dos resíduos da construção e demolição in loco (GONÇALVEZ-DIAS, 2009).

A localização por coordenadas geográficas foi demarcada mediante o uso do GPS - Global Positioning System, marca Garmin, modelo Etrex 10, das quais foram pontuadas por Latitude e Longitude em Graus, Minutos e Segundos.

Para a apresentação das feições urbanas do município de Presidente Bernardes-SP foi realizado um trabalho de campo a fim de se verificar as características e assim definir as tipologias de ocupação do perímetro urbano. A base para a classificação das áreas por tipologia de edificação foi o registro fotográfico e interpretação das feições urbanas (FONSECA, 2008). Os aspectos observados foram padrão construtivo, porte da edificação, características do terreno, características do bairro, infraestrutura urbana local (guias, calçadas, condições de 
pavimento) e finalidade da edificação Residencial ou comercial.

\section{Objeto de estudo}

O trabalho foi desenvolvido no município paulista de Presidente Bernardes-SP localizado na latitude $22^{\circ} 00^{\prime} 22^{\prime \prime} \mathrm{S}$ e a longitude $51^{\circ} 33^{\prime} 11^{\prime \prime} \mathrm{O}$, e estando a uma altitude de 429 metros. O município possui uma população de 13.667 habitantes e uma área total que corresponde a $749,233 \mathrm{~km}^{2}$ (IBGE, 2012b) e o mesmo está localizado distância de $578 \mathrm{~km}$ da capital do estado São Paulo (Figura 1).

A economia do município é baseada no setor de serviços, esta ocupa a maior parcela do produto interno bruto municipal, seguido pela agricultura e pelo setor da indústria. O salário médio mensal no ano de 2015 da população girava em torno de 2 salários mínimos e a população empregada em relação à população total era de $17.8 \%$ (IBGE, 2015).

Figura 1 - Mapa de localização do município de Presidente Bernardes-SP

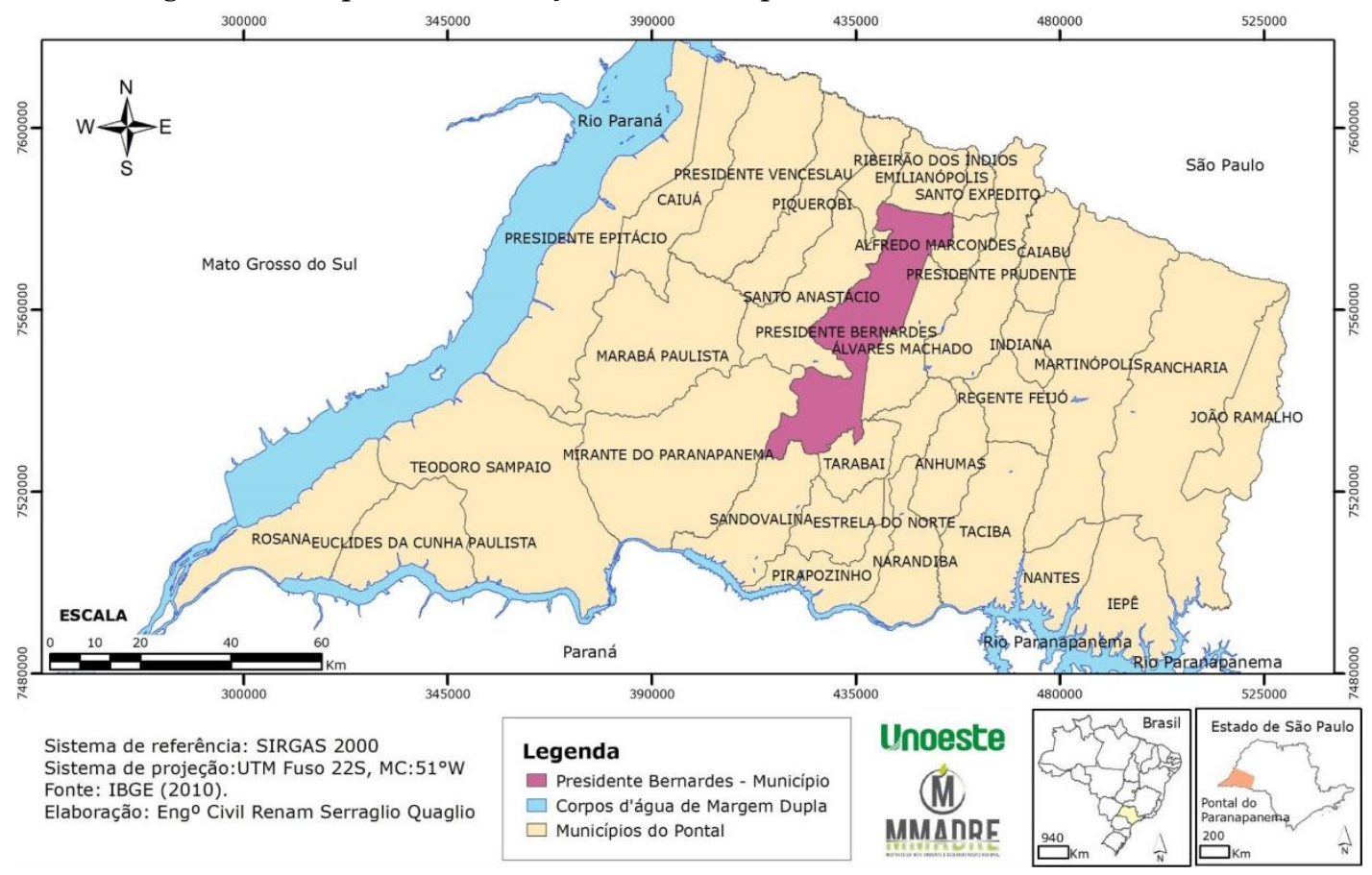

Fonte: IBGE (2015) Organização: Quaglio (2017)

Para a realização de uma análise comparativa entre o descarte irregular de resíduos da construção e demolição e seus possíveis impactos ambientais a área de estudo foi delimitada no perímetro urbano do munícipio e nos acessos periféricos, visto que muitos dos descartes apontados inicialmente ocorriam em estradas rurais e prolongamento de vias da cidade.

\section{RESULTADOS E DISCUSSÃO}

A caracterização das tipologias e padrões construtivos a partir da leitura das feições urbanas em Presidente Bernardes-SP foi realizada com o intuito de relacionar os pontos de descarte e a região em que os mesmos se encontram. Os aspectos observados foram padrão construtivo e porte da edificação, características do terreno, características do bairro, infraestrutura urbana local (guias, calçadas, condições de pavimento) e finalidade da edificação - Residencial ou comercial. É importante salientar que o município não apresenta mapa algum de zoneamento urbano e que as informações sobre regras e padrões de ocupação são descritos no Plano diretor (Lei n 2.115 de 02 de março de 2.010) de forma sucinta, sem elencar quais faixas territoriais do mesmo são restritas a expansão. A partir destas condições o município foi dividido em cinco classes de ocupação que são: Centro, loteamentos residenciais, bairros residenciais A e bairros residenciais B e conjuntos habitacionais (PRESIDENTE BERNARDES, 2010).

A área caracterizada como centro urbano apresenta bons padrões de infraestrutura com 
pavimentos de boa qualidade e atendimento dos serviços ligados ao saneamento básico, às edificações são de médio porte e em grande maioria de finalidade comercial contando com grande fluxo de veículos e transeuntes. Para Fonseca (2011) o parcelamento do solo é o movimento inicial da estruturação urbana que irá condicionar as relações dos habitantes com sua cidade e tem uma forte influência na estruturação física das práticas sociais urbanas

A segunda tipologia de ocupação denominada como loteamentos residenciais referem-se às áreas de expansão no município com finalidade residencial, podemos verificar essas áreas na zona nordeste e sul do município, são novos bairros com menos de 10 anos de surgimento e que apresentam uma parcela dos lotes ainda não edificados, além disto, verificam-se deficiências na infraestrutura urbana como ruas não pavimentadas, ausência de calçamento e lotes com disposição de resíduos. As edificações implantadas nesses loteamentos são térreas em alvenaria e podem ser consideradas de padrão médio, visto que os lotes possuem área inferior a $250 \mathrm{~m}^{2}$. Para Wall e Waterman (2012) o próprio sistema capitalista promove uma distribuição desigual dos recursos e oportunidades entre os indivíduos, deste modo, e as cidades se tornam naturalmente estratificadas em se estratificar em zonas mais ricas e zonas mais pobres

Conforme levantamento de campo em 2019, os bairros residenciais A sãos caracterizados por edificações de grande porte e terrenos com área acima de $400 \mathrm{~m}^{2}$, a infraestrutura é considerada de qualidade desde os serviços de saneamento a pavimentação. O padrão construtivo é composto por residências assobradadas ou térreas em alvenaria, estes locais se caracterizam pela ocupação da parcela da população com maior concentração de renda, como acentua Acosta (2016).

Os bairros residenciais tipo B apresentam edificações de médio a pequeno porte, são as áreas ocupadas ao entorno da região central e possuem infraestrutura instalada e serviços com algumas deficiências (pavimentos degradados e calçadas acompanhando as variações do relevo e impedindo a mobilidade). Benevolo (2012) observa que a desigualdade social promove acesso desequilibrado às infraestruturas e serviços públicos básicos na cidade e que as disparidades sociais criam ambientes inadequados e indignos, diante da cidade formal.
Outro modo de ocupação do perímetro urbano do município são os conjuntos habitacionais de interesse social estes são formados a partir de programas de habitação do poder público e objetivam viabilizar o acesso à moradia adequada aos segmentos populacionais de renda familiar baixa. Nestes bairros é possível verificar edificações padronizadas, entretanto como o decorrer dos anos estas são ampliadas sem algum controle infringindo o coeficiente mínimo de permeabilidade dos lotes. Estes espaços acentuam as desigualdades e a vulnerabilidade social, enfocada por Penna e Ferreira (2014).A infraestrutura é classificada como boa com exceção ao passeio púbico que muitas vezes é precário ou ainda inexistente. A figura 2 mostra a setorização das feições urbanas em relação aos pontos de descarte inadequado de RCD no município.

É possível observar na figura 1 que a região central da cidade não apresenta pontos de descarte irregular tal fato pode ser justificado pelo grande fluxo de pessoas e veículos o que inviabiliza a ação ilegal (ALBUQUERQUE, 2015).

A maioria dos pontos diagnosticados é localizada nas áreas periféricas da cidade, principalmente em terrenos não edificados e proximidades de estradas e acessos não pavimentados, segundo Piovezan Jr. (2007) os pequenos geradores de RCD utilizam veículos de caçamba como carroças, carros e camionetes para transportarem esses resíduos com a finalidade de diminuição dos custos das obras, visto que o valor de transporte se torna inferior ao praticado pelas empresas de caçamba.

Segundo Albuquerque (2015) a dinâmica da deposição irregular do RCD na cidade do RecifePE está diretamente relacionada com os impactos da forma urbana sobre o meio ambiente. A predominância destes resíduos nos pontos de deposição irregular influi na organização espacial do território e interfere no equilíbrio da composição urbanística.

A figura 3 delimita os 40 pontos pesquisados mediante uma análise da caracterização dos resíduos encontrados, uma estimativa de montante dos resíduos dispostos de forma inadequada, bem como os percentuais contributivos de resíduos de cada ponto. O volume do aterro municipal não foi estimado devido à grande parcela de outros resíduos depositados em conjunto, principalmente os de poda e pneumáticos. 
Figura 2: Pontos de descarte e classificação das feições urbanas em Presidente Bernardes-SP

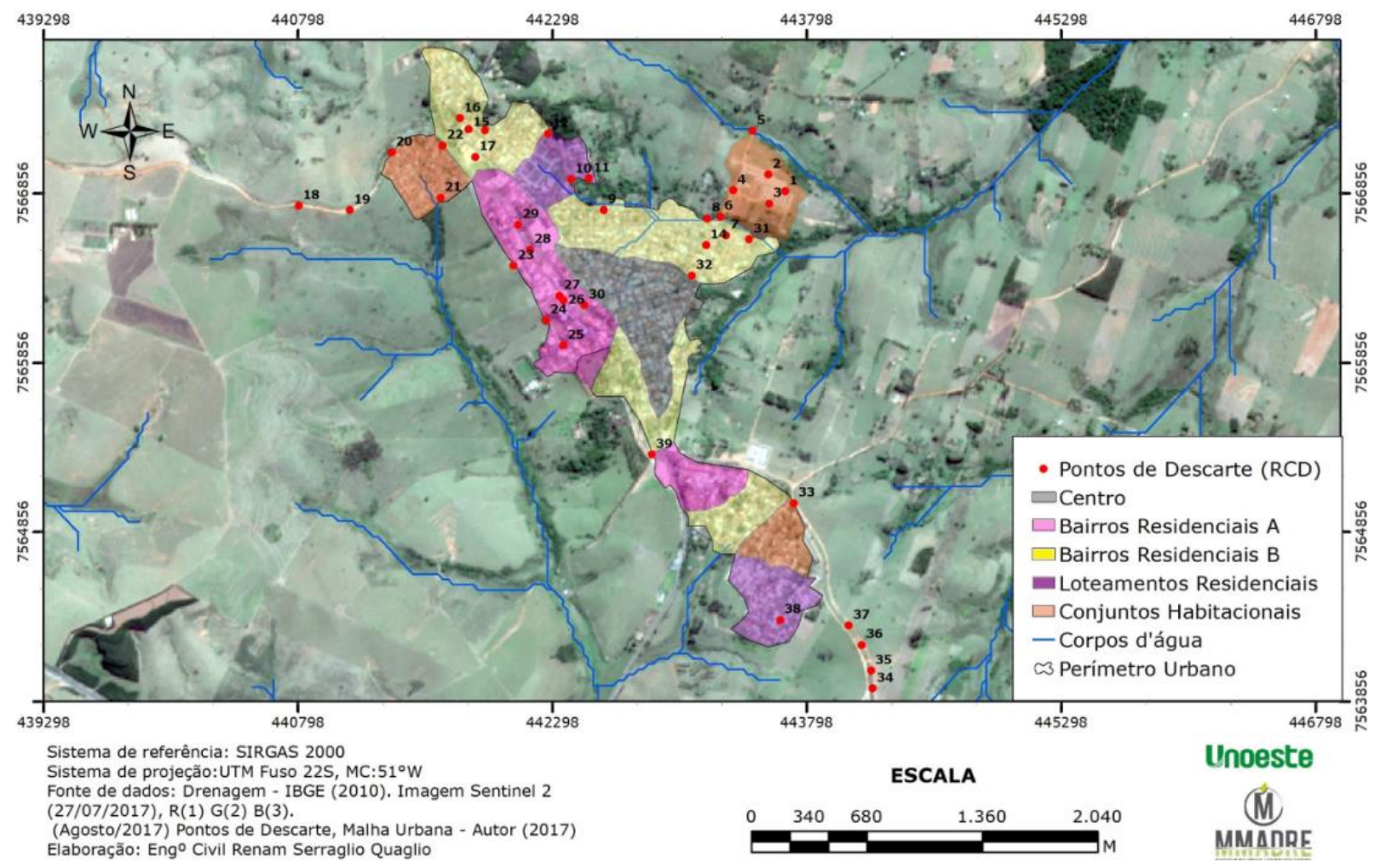

Fonte: Quaglio (2017)

Figura 3: Classes e volumes dos RCD nos pontos coletados em Presidente Bernardes-SP.

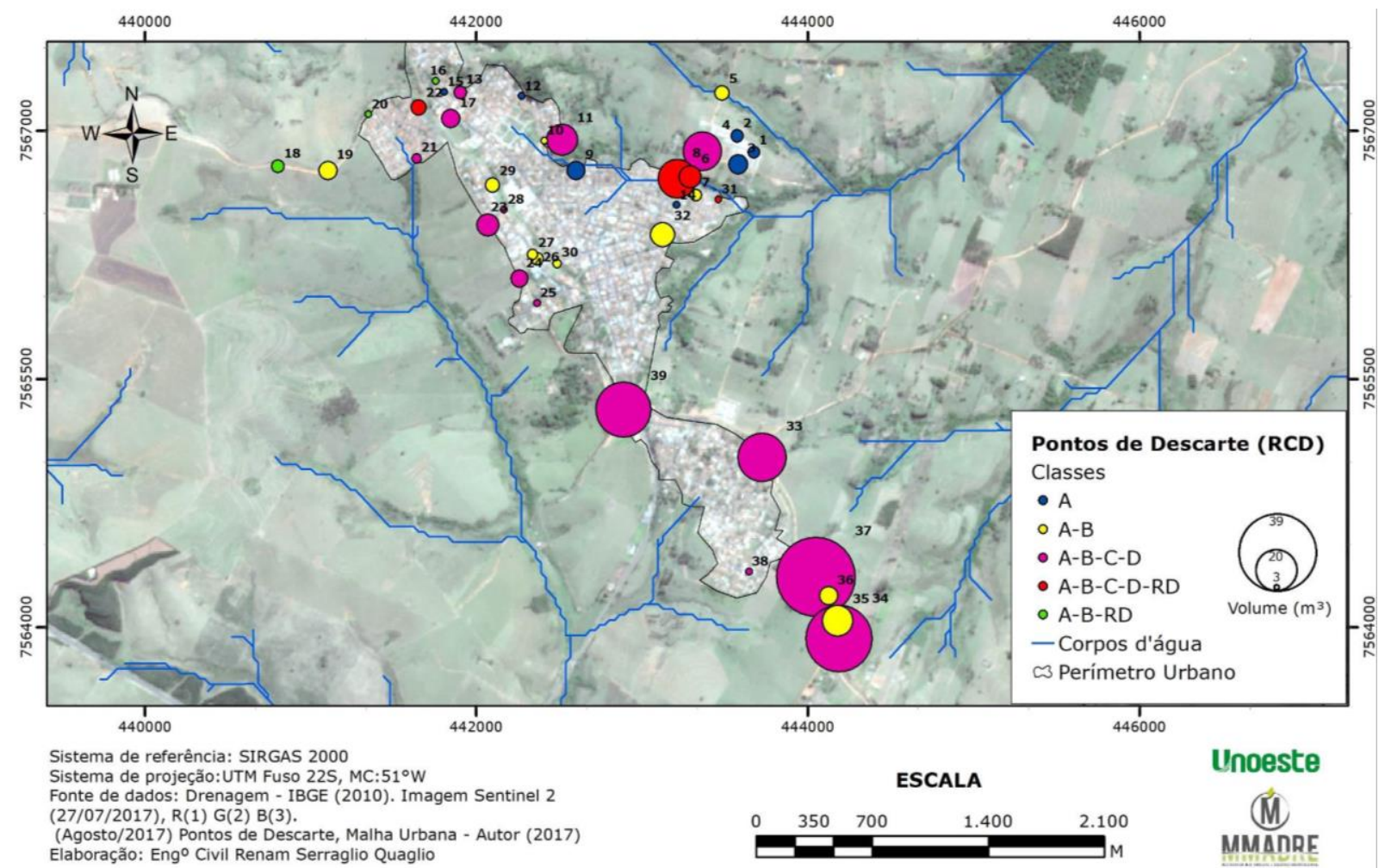

Fonte: Quaglio (2017).

Os dados apresentados pela Figura 2 são preocupantes quanto ao volume descartado de forma irregular e as características dos RCD encontrados, visto que estes podem comprometer 
a fragilidade ambiental do meio, o trabalho de Albuquerque (2015) também corrobora com estes dados.

Ainda é possível observar que um grande número de pontos de descarte inadequado está localizado nas proximidades dos conjuntos habitacionais. De acordo com Córdoba, Martins Filho e Lino (2014) a estimativa percentual da composição de RCD gerados em construções habitacionais em São Luís-MA teve a predominância de materiais cerâmicos (55\%), concreto/argamassa (10\%), papelão (10\%) e gesso (8\%). Tais aspectos corroboram na compatibilidade entre os resíduos de maior volume de RCD se encontra depositado nas áreas periféricas apontadas como bota-fora clandestino (JOHN, 2010).

Atualmente existe somente uma empresa que opera o serviço de coleta dos RCD mediante ao pagamento de uma taxa. Entretanto a empresa coletora não possui área licenciada para a disposição dos RCD, e segundo informações da Secretaria de Meio Ambiente de Presidente Bernardes-SP, em novembro de 2017 parte dos resíduos recolhidos são utilizados na recuperação de estradas rurais e controle de erosões, o restante é destinado para o aterro municipal.

A multiplicidade de pontos de descarte nas proximidades de loteamentos e conjuntos habitacionais pode ser justificada pelo fato dessas áreas estarem em processo de formação apresentando inúmeras construções, já as unidades habitacionais apresentam um processo de ampliação logo que são entregues aos moradores (FERREIRA et al., 2014; PIOVEZAN JR, 2007).

Dos 40 pontos pesquisados cinco apresentaram um percentual acima da relevância de maior ou igual a 5\%. A Tabela 1 representa os cinco pontos citados na afirmação anterior.

Tabela 1: Pontos com relevância com valores iguais ou maiores que 5\% de do Volume Total Estimado.

\begin{tabular}{lll}
\hline PONTO & VOLUME $\left(\mathbf{m}^{\mathbf{3}}\right)$ & \% \\
\hline 4 & 19,2 & $5,05 \%$ \\
33 & 24 & $6,31 \%$ \\
34 & 33 & $8,68 \%$ \\
37 & 39 & $10,26 \%$ \\
39 & 27 & $7,10 \%$ \\
\hline TOTAL & $\mathbf{1 4 2 , 2}$ & $\mathbf{3 7 , 4 0 \%}$ \\
\hline
\end{tabular}

Fonte: Quaglio (2017).

Os pontos 33, 34 e 37 estão localizados na Estrada Rural PSB 030 - Linha Férrea e juntos correspondem a $25,25 \%$ do valor total estimado, tais números corroboram com a falta de cumprimento à legislação ambiental por parte da empresa responsável pela coleta, transporte e destinação final, bem como o Poder Público Municipal, Estadual e Federal como entes fiscalizadores e reguladores. A estrada rural supracitada é concebida por estes como uma área de destinação de resíduos da construção e demolição, bem como outros resíduos já identificados nesta pesquisa.

Desta forma, segundo Klein e Gonçalves-Dias (2017) existe uma deterioração da paisagem urbana oriunda da disposição de RCD identificada no momento que os RCD são dispostos de maneira incorreta, visto que são destinados a terminar sua vida útil sendo despejado a céu aberto em aterros sanitários, causando danos ambientais como degradação e poluição do solo e corpos d'água e mananciais.
Ao relacionar o volume estimado nos pontos e subdividi-los de acordo com o local de disposição irregular se torna possível verificar em quais tipos de pontos o descarte se torna recorrente e assim notificar os proprietários ou responsáveis legais. A tabela 2 denota a relação entre a quantidade de pontos analisados, a tipologia em que eles são caracterizados e o percentual que cada caracterização ocupa na amostra.

Os locais com maior recorrência de ações de descarte são os terrenos particulares configurados como Propriedade Privada possuindo 12 pontos, ou seja, compõem 30\% dos locais vistoriados. Em seguida vem às ruas e calçadas do município (Vias púbicas) com $27,5 \%$, é importante considerar que essa disposição é extremamente prejudicial às estruturas de drenagem urbana, pois com as chuvas os materiais são carregados e obstruem as bocas de lobo e galerias ocasionando enchentes. 
Tabela 2: Relação do Quantitativo dos Locais por sua Caracterização.

\begin{tabular}{lcc}
\hline \multicolumn{1}{c}{ CARACTERIZAÇÃO DO LOCAL } & PONTOS & \% \\
\hline Área Institucional & 4 & 10 \\
Propriedade Privada & 12 & 30 \\
Via Pública & 11 & 27,5 \\
Estrada Rural - A.P.P. & 1 & 2,5 \\
A.P.P. - Córrego & 3 & 7,5 \\
Estrada Rural & 2 & 5 \\
Estrada Rural - Linha Férrea & 6 & 15 \\
Aterro Municipal & 1 & 2,5 \\
\hline \multicolumn{1}{c}{ TOTAL } & $\mathbf{4 0}$ & $\mathbf{1 0 0}$ \\
\hline
\end{tabular}

Fonte: Quaglio (2017).

Os trabalhos de Pinto, Santos e Catunda (2015) e de Piovezam Junior e Silva (2007) atentam para as consequências do descarte incorreto dos RCD, tais como: assoreamento dos cursos d'água, degradação de áreas de manancial e de proteção ambiental permanente, instabilidade de encostas, obstrução de vias de pedestres e de veículo e obstrução de sistemas de drenagem. A Figura 4 compreende a descrição do percentual disposto em cada área estudada.

Figura 4: Relação percentual do volume calculado por tipologia de área de disposição.

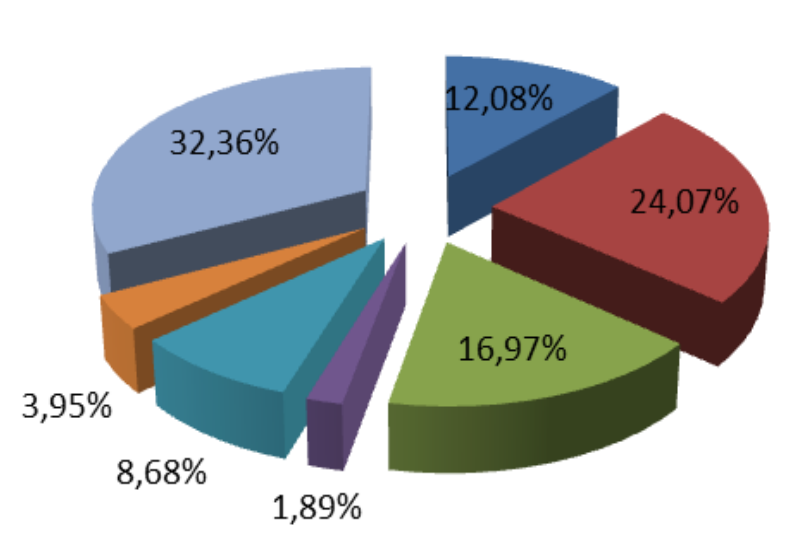

Fonte: Quaglio (2017).

\section{- Área Institucional}

- Propriedade Privada

- Via Pública

- Estrada Rural - A.P.P.

A.P.P. - Corrégo

- Estrada Rural

Estrada Rural - Linha

Férrea
A partir dos dados pode-se concluir que a área identificada como Estrada Rural - Linha Férrea apresenta o maior volume de RCD estimado em cerca de $123 \mathrm{~m}^{3}$, seguido pelas propriedades privadas com cerca de $24,07 \%$ e também pelas vias públicas com $16,97 \%$ da porção analisada. É importante considerar que os materiais naturais, como a areia - a qual muitas vezes é retirada de rios - também agride o meio ambiente, pois modifica a geomorfologia do direcionamento fluvial, depreciação da qualidade da água e aumenta a incidência de processos erosivos na área rural (NOGUEIRA, 2016). Desta forma, torna-se importante lembrar da gestão correta dos RCD (WEISSHEIMER; KERN, 2014) e as formas de reciclagem dos resíduos (GEHRMANN; HIEBEL; SIMON, 2017).

A Figura 5 apresenta a reincidência de classes dos RCD avaliados nos pontos de disposição irregular, e também a verificação do lixo doméstico qualificando o poder de atratividade dos RCD. 
Figura 5 - Reincidência de classes dos RCD nos pontos avaliados.

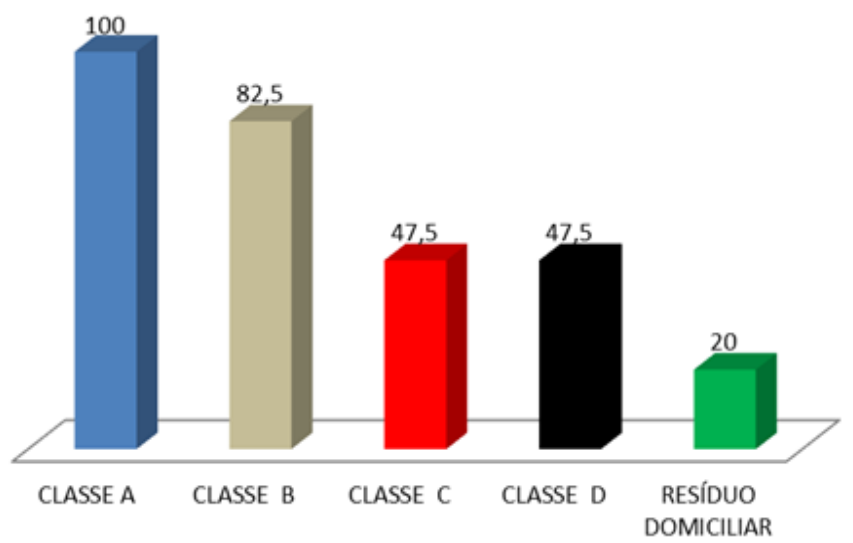

Fonte: Quaglio (2017).

Analisando as descrições apresentadas na Figura 4 podemos compreender que a incidência de materiais classificados como A, foi observada em 100\% (40 pontos investigados) são resíduos oriundos de cerâmicas, argamassas, concretos e madeiras, pois são os insumos mais utilizados e que possuem o maior volume, bem como estes não apresentam riscos de contaminação aos recursos naturais.

A classe B está presente em $82,5 \%$ (33 pontos) são resíduos originários de: plásticos, papelões, metais, vidros e embalagens vazias, estes não causam danos ou impactos se destinados de forma irregular no meio ambiente. Souza, Marques e Araújo (2019) ainda ressalta que um outro impacto decorrente da elevada geração de RCD e seu descarte irregular, diz respeito à atração que as deposições de RCD passam a exercer sobre outros tipos de resíduos sólidos.

Já a classe C foi identificada em 47,5\% (19 pontos) são resíduos de provenientes de restos de materiais dos quais não há a viabilidade de reciclagem ou reuso e os resíduos classificados como D foram reconhecidos em 19 pontos da amostra resultando em de $47,5 \%$ dos pontos, sendo identificados como materiais perigosos oriundos do processo de construção.

Córdoba (2010) cita que apesar da quantidade percentual de resíduos Classe D ser praticamente nula $(0,1 \%)$, não se pode extinguir a possibilidade desses resíduos estarem incorporados a resíduos de outras classes, por exemplo, despejos de tintas, solventes e óleos absorvidos pelos poros de resíduos como solo, areia, argamassas, cerâmicos e concreto.

A abordagem dos resíduos domiciliares neste estudo foi relacionada com a sua reincidência em $20 \%$ dos pontos e também no apontamento da literatura como fator de impacto ambiental, os materiais encontrados eram embalagens plásticas, vidros, papéis, matéria orgânica. (GONÇALVES, 2016).

Em um estudo realizado por Albuquerque (2015), foram identificados valores semelhantes aos encontrados nesta pesquisa, principalmente na verificação de $R C D$ de classe $A$ e $B$, tal fato representa um grande potencial a reutilização e reciclagem destes materiais, como apontado por Zordan (2002); Meng et al. (2018) e Hassan et al. (2019).

Desta forma, podemos dizer que o impacto ambiental causado pela má gestão dos RCD é devido a não captação compromissada, a inexistência de políticas públicas que disciplinem a destinação dos resíduos e tudo isso associado a um ineficaz gerenciamento ambiental de alguns agentes ligados à gestão dos RCD, impõe-se à população um expressivo número de áreas degradadas denominadas, conforme Pinto e Gonzáles (2005), de bota-foras clandestinos ou de deposições irregulares.

Segundo Nogueira (2016), a maioria dos pontos de deposição incorreta, na maior parte das vezes, resultam do descarte de resíduos provenientes de pequenas obras ou reformas por processos de autoconstrução, que contribuem com pequenos volumes de RCD. Para diminuir a geração de resíduo e eliminar os impactos ambientais negativos promovendo a sustentabilidade no setor de construção civil, esforços devem ser criados para o uso dos produtos de materiais na construção sustentáveis (MENG et al., 2018)

É importante salientar que a construção de uma gestão diferenciada baseada em ações que solidificam a sustentabilidade ambiental tem como benefícios a diminuição dos custos de limpeza urbana, redução de impactos ambientais e ganhos na questão de saúde pública, com o benefício de substituição de agregados condicionais por agregados reciclados (LONG, 
2018).

Desta forma, torna-se interessante apresentar um resumo dos resultados obtidos na pesquisa sobre os impactos do RCD no município de Presidente Bernardes enfocando os pontos de descarte.

Quadro 1 - Relação dos impactos ambientais e sanitários nos pontos de descarte inadequado em Presidente Bernardes.

\begin{tabular}{|c|c|c|}
\hline Impactos ambientais e sanitários & Descrição & Pontos \\
\hline Atrativo para outros resíduos & $\begin{array}{c}\text { Acúmulo de resíduos de outras origens em } \\
\text { conjunto com os RCD dispostos } \\
\text { irregularmente }\end{array}$ & Todos os pontos \\
\hline Assoreamento de córregos & $\begin{array}{l}\text { Transporte de solos e materiais pelo fluxo de } \\
\text { rios causando seu arrasamento }\end{array}$ & $5,6,8,9,31$ \\
\hline Degradação de área de preservação permanente & $\begin{array}{c}\text { Alocação de RCD em áreas de preservação } \\
\text { permanente }\end{array}$ & $5,6,8,9,10,11,12,21,31$ \\
\hline Atração de vetores (ratos e insetos) & Proliferação de vetores nas pilhas de RCD & Todos os pontos \\
\hline $\begin{array}{l}\text { Ruídos e poeira nos locais de disposição } \\
\text { irregular }\end{array}$ & $\begin{array}{l}\text { Movimentação de transportadores nos locais } \\
\text { de disposição }\end{array}$ & $33,35,36,37,40$ \\
\hline Erosão do solo & Carreamento de solos nos locais de descarte & $\begin{array}{c}5,6,8,9,10,11,12,18,19,2 \\
1,31,33,35,36,37,40 \\
\end{array}$ \\
\hline Alteração da qualidade da água & Aumento de material disperso na água & $5,6,8,9,31$ \\
\hline Degradação das áreas de descarte irregular & $\begin{array}{l}\text { Alteração das características físicas e } \\
\text { biológicas das áreas }\end{array}$ & Todos os pontos \\
\hline Descarte dos RCD no aterro sanitário municipal & $\begin{array}{l}\text { Sobreposição de resíduos impedindo a } \\
\text { recuperação da área do aterro }\end{array}$ & 40 \\
\hline
\end{tabular}

Fonte: Quaglio (2017).

Com todas as análises e interpretações apresentadas neste estudo chegamos à compreensão de que os RCD causam danos ambientais como degradação e poluição do solo e corpos d'água e mananciais, bloqueio do sistema de drenagem urbano, crescimento de enchentes, proliferação de doenças, degradação da paisagem urbana e outros vetores de degradação urbana.

Contudo, torna-se interessante verificar as informações sobre os possíveis impactos ambientais em outros municípios brasileiros, expostas no Quadro 2.

As cidades vêm enfrentando sérios problemas relacionados à geração de RCD e consequentemente essa falta de conhecimento sobre alternativas para o seu destino gera consideráveis transtornos à população e ao meio ambiente.

Entretanto, cabe ressaltar que diversos autores (ALBUQUERQUE, 2015; CÓRDOBA, 2010; CÓRDOBA, 2014; PINTO; SANTOS; CATUNDA,
2015; KLEIN.; GONÇALVES-DIAS, 2017; MORAIS, 2006; MARTINS, 2012) afirmam o as consequências ambientais dos RCD enfocando a falta de gerenciamento pelo poder público. Já os outros autores (PIOVEZAN JR., 2007; TANGA et al., 2020) afirmam que grande parte do RCD é constituído por uma parcela de materiais recicláveis e quando corretamente destinado pode se transformar em uma indústria geradora de recursos com plena capacidade de convivência da escala produtiva com o meio ambiente. No município de Presidente Bernardes também foi verificado (quadro 1) os vários impactos ambientais ocasionados pelo descarte em locais inadequados geralmente em pontos distantes do centro, pratica também apontada em outros trabalhos (KLEIN; DIAS, 2017; CÓRDOBA, 2010; ALBUQUERQUE, 2015). Entretanto, falta exemplos de mecanismos de gestão integrada dos RCD respeitando as particularidades regionais e suas características socioeconômicas, culturais, geográficas, educacionais e políticas. 
Quadro 2 - Principais impactos ambientais dos RCD na literatura (2006-2020).

\begin{tabular}{|c|c|c|c|}
\hline Autores & Locais & Impactos & Desfechos \\
\hline $\begin{array}{l}\text { Souza, Marques, } \\
\text { Araujo (2019) }\end{array}$ & Brasil & $\begin{array}{l}\text { destaca as regulamentações } \\
\text { prescritas, sob caráter jurídico, a } \\
\text { serem priorizadas }\end{array}$ & $\begin{array}{l}\text { Auxilia na tomada de } \\
\text { decisões envolvendo resíduos } \\
\text { sólidos }\end{array}$ \\
\hline Albuquerque. (2015) & Recife & $\begin{array}{l}\text { Impacto socioambiental da } \\
\text { deposição irregular dos resíduos } \\
\text { da construção e demolição }\end{array}$ & $\begin{array}{l}\text { Ausência de } \text { uma Plano } \\
\text { Diretor que possua um } \\
\text { zoneamento } \begin{array}{c}\text { ambiental } \\
\text { (proteção de áreas verdes) }\end{array}\end{array}$ \\
\hline Córdoba (2010) & São Carlos-SP & $\begin{array}{llr}\text { Estudo do } & \text { sistema } & \text { de } \\
\text { gerenciamento } & \text { integrado } & \text { de } \\
\text { resíduos de } & \text { construção } & \text { e } \\
\text { demolição do } & & \end{array}$ & $\begin{array}{l}\text { Pouca } \\
\text { ambiental, prejudicaram os } \\
\text { resultados }\end{array}$ \\
\hline Córdoba (2014) & $\begin{array}{l}\text { Morada do Sol. São } \\
\text { Luís, MA }\end{array}$ & $\begin{array}{l}\text { Plano de gerenciamento de } \\
\text { resíduos da construção civil do } \\
\text { loteamento social: }\end{array}$ & $\begin{array}{l}\text { Construção de ferramentas } \\
\text { essenciais que transcendam } \\
\text { à reciclagem }\end{array}$ \\
\hline $\begin{array}{l}\text { Pinto.; Santos dos.; } \\
\text { Catunda (2015) }\end{array}$ & $\begin{array}{l}\text { Parnamirim/RN/Bras } \\
\text { i }\end{array}$ & $\begin{array}{l}\text { Percepção da } \text { legislação } \\
\text { ambiental, gestão e destinação } \\
\text { final dos RCD - Resíduos da } \\
\text { Construção e Demolição }\end{array}$ & $\begin{array}{l}\text { Traz uma discssão sobre a } \\
\text { importância de ua legislação } \\
\text { municipal adequada para a } \\
\text { destinação dos RCD }\end{array}$ \\
\hline $\begin{array}{l}\text { Klein.; Gonçalves- } \\
\text { Dias. (2017) }\end{array}$ & São Paulo- SP & $\begin{array}{l}\text { A Deposição } \\
\text { Irregular } \\
\text { Resíduos da Construção Civil }\end{array}$ & $\begin{array}{l}\text { Os resultados mostraram que } \\
\text { consequências ambientais da } \\
\text { deposição inadequada }\end{array}$ \\
\hline Morais (2006). & Uberlândia- MG & $\begin{array}{llr}\text { Diagnóstico } & \text { da deposição } \\
\text { clandestina de resíduos } & \text { de } \\
\text { construção e demolição em } & \text { em } \\
\text { bairros periféricos }\end{array}$ & $\begin{array}{l}\text { Os resultados apontam para } \\
\text { as consequências ambientais } \\
\text { do RCD }\end{array}$ \\
\hline Martins (2012). & São Carlos- SP & $\begin{array}{l}\text { Gestão e gerenciamento de } \\
\text { resíduos da construção civil em } \\
\text { obras de grande porte }\end{array}$ & $\begin{array}{l}\text { O local de estudo possui } \\
\text { instrumentos } \\
\text { planejamento capazes de } \\
\text { promover a construção de um } \\
\text { desenvolvimento com } \\
\text { crescimento econômico e } \\
\text { prudência ecológica. }\end{array}$ \\
\hline Piovezan Jr. (2007) & Snata Maria -RGS & $\begin{array}{l}\text { Avaliação dos resíduos } \\
\text { construção civil (rcc) gerados }\end{array}$ & $\begin{array}{l}\text { O estudo permite uma } \\
\text { determinação rápida, para } \\
\text { avaliação e maenjo dos }\end{array}$ \\
\hline $\begin{array}{l}\text { Tanga; Lia; Tamb, } \\
\text { Xue ( 2020) }\end{array}$ & China & $\begin{array}{l}\text { Advanced progress in recycling } \\
\text { municipal and construction solid } \\
\text { wastes for manufacturing } \\
\text { sustainable } \\
\text { materials. }\end{array}$ & $\begin{array}{l}\text { Os resultados indicam que, } \\
\text { embora a inclusão de RCD } \\
\text { em geopolímeros, em } \\
\text { proporção adequada podem } \\
\text { aliviar os efeitos prejudiciais } \\
\text { e facilitar o progresso da } \\
\text { reciclagem. }\end{array}$ \\
\hline
\end{tabular}

Fonte: Quaglio (2017).

\section{CONSIDERAÇÕES FINAIS}

A importância do trabalho de campo é demonstrada na caracterização dos distintos cenários de descarte e interpretação das feições urbanas verificados em cada ponto de disposição irregular, onde foram observadas as tipologias de local de descarte, os volumes que estavam depositados e também os recursos naturais que estavam sendo danificados pela presença dos RCD.

$\mathrm{O}$ estudo enfatizou a necessidade do descarte adequado dos RCD, foi possível verificar que a falta de gerenciamento adequado pode impactar o meio ambiente de forma negativa. Com adoção de políticas públicas direcionadas para a reciclagem de dejetos da Construção Civil é possível diminuir o volume de entulhos depositados em locais impróprios e ainda reaproveitar esse material.

Foi possível constatar que os impactos ambientais e sanitários decorrentes das disposições irregulares se concentram principalmente nas áreas periféricas e distribuídas de maneira desigual, tal condição de distribuição é discutida por alguns autores relacionando com informações de faixas de renda per capta. É importante salientar que grupos específicos sofrem de maneira desproporcional o resultado da degradação ambiental.

A grande parte dos problemas identificados é oriunda da ausência de uma área devidamente licenciada para a destinação ou deposição temporária dos RCD, além disto, a criação de ecopontos para a deposição de pequenos volumes aliada a uma política de fiscalização regular 
resultaria na diminuição dessas áreas de disposição irregular.

Uma questão que deve ser considerada com solução é a reciclagem desses resíduos, mas essa é apenas uma das inúmeras possibilidades que podem ser avaliadas dentro da aplicabilidade do Gerenciamento de Resíduos. A partir do diagnóstico da situação é possível a criação e planejamento de ações e propostas direcionadas a formalização de um sistema de gestão diferenciada baseada na redução, reutilização, reciclagem, fiscalização eficiente e disposição final ambientalmente correta.

\section{REFERÊNCIAS}

ACOSTA, S. As recentes tendências do mercado imobiliário costarriquenho. Revista Geo UERJ. Rio de Janeiro, v. 20, n. 28, p.1-25, 2016. ALBUQUERQUE, D. M. S. Impacto socioambiental da deposição irregular dos resíduos da construção e demolição na cidade do Recife-PE. 2015. Dissertação (Mestrado em Construção Civil) - Programa de Pós-Graduação em Engenharia Civil, Escola Politécnica, Universidade de Pernambuco, Recife, 2015.

BRASIL. Lei $\mathrm{n}^{\circ} 12.305$ de 02 de agosto de 2010 . Institui a Política Nacional de Resíduos Sólidos; altera a Lei $n^{\circ} 9.605$, de 12 de fevereiro de 1998; e dá outras providências. Diário Oficial da União, Brasília, nº 147, p. 3, 03 de ago. 2010.

BARROS, M. V., SOUZA, J. T. Plano de gerenciamento de resíduos sólidos da construção civil: um panorama de análise a partir da Resolução 307 do CONAMA. Revista Gestão Industrial, Ponta Grossa, v. 13, n. 1, p. 139. 153, out./dez. 2017.

BENEVOLO, L. História da cidade. Tradução de Silvia Mazza. São Paulo: Perspectiva, 2012.

CARLOS, Ana. Fani. Alessandri. O espaço urbano: novos escritos sobre a cidade. São Paulo, Contexto, 2004.

CONSELHO NACIONAL DO MEIO AMBIENTE (CONAMA); Ministério do Meio Ambiente Resolução n⿳. 30705 de julho de 2002. Diário Oficial da República do Brasil. Brasília. 2002.

CÓRDOBA, R. E. Estudo do sistema de gerenciamento integrado de residuos de construção e demolição do município de São Carlos - SP. 406 p. Dissertação (Mestrado em Hidráulica e Saneamento) - Escola de Engenharia de São Carlos, Universidade de São Paulo, São Carlos, 2010.

CÓRDOBA, R. E; MARTINS FILHO, C. A. S; LINO, J. R. Plano de gerenciamento de resíduos da construção civil do loteamento social Morada do Sol. São Luís, MA: FAIUFSCar, 2014.

FERREIRA, A. C. A.; COSTA, F. M. V.; DIAS, I. C. T; SANTOS, S. Gestão de Resíduos Sólidos na Construção Civil. Revista Pensar Engenharia, Belo Horizonte, v.2, n. 2, p. 1- 18, 2014.

FERNANDES, Mário Gonçalves. Urbanismo contemporâneo e morfologia urbana nas cidades do norte de Portugal (1852-1926). In: Cidades. Presidente Prudente: GEU, n.8, v.5, p.329-354, 2008.

FONSECA, E. S. Estudo da distribuição espacial de parasitoses e condições de saneamento básico para o município de Ouro Preto/MG, com o apoio do geoprocessamento. 2008. 177 f. Dissertação (Mestrado) - Programa de Pós-Graduação em Geografia, Instituto de Geociências, Universidade Federal de Minas Gerais - UFMG.

FONSECA, C. D. Arraiais e vilas d'el rei: espaço e poder nas Minas setecentistas [online]. Belo Horizonte: Editora UFMG, 2011. https://doi.org/10.7476/9788542303070.

GEHRMANN, H-J.; HIEBEL, M.; SIMON, F. G. Methods for the Evaluation of Waste Treatment Processes. Journal of Engineering. Berlim, p. 1-14,2017. https://doi.org/10.1155/2017/3567865

GOMES, M. H. S. C.; OLIVEIRA, E. C.; BRESCIANI, L. P.; PEREIRA, R. S. Polí-tica Nacional de Resíduos Sólidos: perspectivas de cumprimento da lei 12.305/2010 nos municípios brasileiros, municípios paulistas e municípios da região do ABC. Rev. Adm. UFSM, v. 7, Edição Especial, p. 93-110, 2014.

GOMES, S. de C.; ZHOU, J. L., LI, W.; LONG, G. Progress in manufacture and properties of construction materials incorporating water treatment sludge: a review S. Resour. Conserv. Recycl., Michigan, v. 145, p. 148-159, 2019

http:doi.org/10.1016/j.resconrec.2019.02.032

GONÇALVES, B. B.; DIAS, J. F. Resíduos domiciliares recicláveis: prospecção para cidade de médio porte. Observatorium: Revista Eletrônica de Geografia, Uberlândia, v.1, n.1, p. 84-104, 2009.

GOUVEIA, N. Resíduos sólidos urbanos: impactos socioambientais e perspectiva de manejo sustentável com inclusão social. Ciênc. Saúde coletiva, v.17, n.6, p.1503-1510, jun. 2012.

GUIMARAES, L da S. O modelo de urbanização brasileiro: notas gerais. GeoTextos, vol. 12, n. 1 p. 13-35, jul. 2016. http://dx.doi.org/10.9771/19845537geo.v12i1.14 084

HASSAN, A.; ARIF, M; SHARIQ, M.. Use of geopolymer concrete for a cleaner and 
sustainable environment - a review of mechanical properties and microstructure. J. Cleaner Prod., 223 (2019), pp. 704-728 DOI: https://doi.org/10.1016/j.jclepro.2019.03.051

IBGE - Instituto Brasileiro de Geografia e Estatística. Censo Demográfico 2010. Rio de Janeiro: IBGE, 2010.

Pesquisa Nacional de Saneamento

Básico 2008. Rio de Janeiro: IBGE, 2012a. Censos demográficos dos anos de

2000 a 2010. Rio de Janeiro: IBGE. 2012b .Perfil dos Municípios Brasileiros Rio de Janeiro: IBGE, 2015 Disponível em: https://ww2.ibge.gov.br/home/estatistica/econo mia/perfilmunic/2015/default.shtm Acesso: 15 de julho de 2018

JOHN, V. M. Reciclagem de resíduos na construção civil - contribuição à metodologia de pesquisa e desenvolvimento. São Paulo, 2010. 102p. Tese (livre docência) - Escola Politécnica, Universidade de São Paulo, São Paulo, 2010.

KLEIN, F. B.; DIAS, S. L. F. G. A Deposição Irregular de Resíduos da Construção Civil No Município de São Paulo: um estudo a partir dos instrumentos de políticas públicas ambientais. Desenvolv. Meio Ambiente, Curitiba v. 40, p. 483-506, abril 2017. http://dx.doi.org/10.5380/dma.v40i0.47703

LEFEBVRE, H. A Revolução Urbana. 5 ed. Belo Horizonte: Editora UFMG, 2008.

LEFEBVRE, H. O Direito à Cidade. 8 ed. Itapevi: Nebil, 2016.

LONG, W; LI, H; WEI, J; XING, F; HAN, N. Sustainable use of recycled crumb rubbers in eco-friendly alkali activated slag mortar: dynamic mechanical properties, Prod.Cleaner Prod 204 (2018), pp. 1004-1015

BRITO, J.; BRAVO, M. Indicadores de resíduos de construção e demolição para construções residenciais novas. Ambient. Constr, Porto Alegre, v.11, n.3, p.117-130, 2011. https://doi.org/10.1590/S1678862120110003000 09.

MARQUES NETO, J. C. Gestão dos resíduos de construção e demolição no Brasil. São Carlos: RIMA, 2005

MENG, Y; LING, T. C; MO, K. H; Recycling of wastes for value-added applications in concrete blocks: an overview . Resour. Conserv. Recycl., Michigan, V 138, p. 298-312, 2018 https://doi.org/10.1016/j.resconrec.2018.07.029

MARTINS, F. G. Gestão e gerenciamento de resíduos da construção civil em obras de grande porte: estudos de caso. 2012. 177 p. Dissertação (Mestrado) - Escola de Engenharia de São Carlos, Universidade de São Paulo, São Carlos, 2012

MORAIS, G. M. D. Diagnóstico da deposição clandestina de resíduos de construção e demolição em bairros periféricos de Uberlândia: subsídios para uma gestão sustentável. 2006. 201 f. Dissertação (Mestrado) - Faculdade de Engenharia Civil, Universidade Federal de Uberlândia, 2006.

NOGUEIRA, G. R. F. Extração de Areia em Cursos D’água e Seus Impactos: Proposição de uma Matriz de Integração. Curso de Engenharia Ambiental e Sanitária na Universidade Federal de Juiz de Fora, Juiz de Fora, 29 jul. 2016. Acesso: https://www.ufjf.br/engsanitariaeambiental/file s/2014/02/TFC_Vers\%C3\%A3oFinal.pdf

PANERAI, P. Análise Urbana. Tradução de Francisco Leitão; Revisão técnica de Sylvia Ficher. Brasília: Editora Universidade de Brasília, 2014. 198p.ISBN 85-230-0923-X

PINTO, C. H. C.; SANTOS, A. L. dos.; CATUNDA, A. C. M. M. Percepção da legislação ambiental, gestão e destinação final dos rcd - resíduos da construção e demolição: um estudo de caso em Parnamirim/RN/Brasil. Holos, [S.l.], v. 2, p. 3349, abr. 2015. https://doi.org/10.15628/holos.2015.1528

PINTO, T. P.; GONZÁLEZ, J. L. R. (Coord.) Manejo e gestão de resíduos da construção civil. Brasília, DF: Caixa Econômica Federal, 2005.

PRESIDENTE BERNARDES. Lei ${ }^{\circ} 2.115$ de 02 de março de 2.010. Institui o Plano Diretor Municipal e dispõe sobre a colocação, em vias públicas, de resíduos gerados por demolições, construções e dá outras providências, 2010. Presidente Bernardes: [s.n.], 2010.

PENNA, N. A; FERREIRA, I. B. Desigualdades socioespaciais e áreas de vulnerabilidades nas cidades. Mercator, Fortaleza, v. 13, n. 3, p. 2536, dez. 2014. https://oi.org/10.4215/RM2014.1303.0002

PIOVEZAN JR, G. T. A. Avaliação dos resíduos da construção civil (rcc) gerados no município de Santa Maria. 2007. 76 p.. Dissertação (Mestrado) - Programa de PósGraduação em Engenharia Civil, Universidade Federal de Santa Maria, Santa Maria, 2007 Disponivel

em.

https://repositorio.ufsm.br/handle/1/7924

QUAGLIO, Renam Serraglio. Resíduos da construção e demolição (rc\&d): estudo dos impactos ambientais provocados pelo descarte inadequado no município de Presidente Bernardes - SP. 2017. 118 f. Dissertação (Mestrado em Meio Ambiente e Desenvolvimento Regional) - Universidade do Oeste Paulista, Presidente Prudente, 2017.

SANCHES, M. C. G. Valoração do Serviço de Destinação Final dos Resíduos Gerados na Construção Civil do Município de Salvador, Bahia. 2004. 127 f. Dissertação 
(Mestrado em Desenvolvimento Sustentável) Universidade Nacional de Brasília, Brasília, 2004

SANTOS, M. A natureza do espaço. Técnica e tempo, razão e emoção. $4^{\mathrm{a}}$ ed. São Paulo: Edusp, 2006.

SANTOS, M. R. R.; RANIERI, V. E. L. Critérios para análise do zoneamento ambiental como instrumento de planejamento e ordenamento territorial. Ambiente. \& Sociedade. [online], Campinas, v.16, n.4, pp.43-60, 2013. https://doi.org/10.1590/S1414753X20130004000 04.

SILVA, V. A.; FERNANDES, A. L. T. Cenário do gerenciamento dos resíduos da construção e demolição (RCD) em Uberaba-MG. Soc. \& Nat., Uberlândia, v. 24, n. 2, 333-344, mai/ago. 2012.

SILVA W. R. da; SPOSITO, M. E. B. (orgs.). Perspectivas da urbanização: reestruturação urbana e das cidades. Rio de Janeiro: Consequência Editora, 2017. 230p

SILVA, J. S.; RANIERI, V. E. L. O mecanismo de compensação de reserva legal e suas implicações econômicas e ambientais. Ambiente \& Sociedade, Campinas. v. 17, n. 1, p. 115-132, 2014.

SPOSITO, M. E. B. Cidades médias: reestruturação das cidades e reestruturação urbana. In: SPOSITO, M. E. B. (org.). Cidades médias: espaços em transição. São Paulo: Expressão Popular, 2007.
SOUZA, P. H. R.; MARQUES, M. S. P.; ARAUJO, M. C. P. Análise sobre a gestão de resíduos sólidos da construção civil. Revista Científica Multidisciplinar Núcleo do Conhecimento. São Paulo, v. 7, n. 3, p. 13-35, 2019. Disponível em:https://www.nucleodoconhecimento.com.br/e ngenharia-civil/residuos-solidos

TANGA, Z.; LI, W.; TAM, V.; XUE, C. Advanced progress in recycling municipal and construction solid wastes for manufacturing sustainable construction materials. Resources, Conservation \& Recycling: Michigan, v. 6, n. 10 2020.

https://doi.org/10.1016/j.rcrx.2020.100036

TEIXEIRA, L. P. Desempenho da construção brasileira. Belo Horizonte: UFMG, 2010.

WALL, E. WATERMAN, T. Desenho urbano: Fundamentos de Paisagismo. Tradução técnica de Alexandre Salvaterra. Porto Alegre: Bookman, 2012.

WEISSHEIMER, L. F; KERN, A. P. Classificação Dos Resíduos De Construção: discussão dos critérios da Resolução 307/2002 do CONAMA. 5 ${ }^{\circ}$ Fórum Internacional de Resíduos Sólidos, São Leopoldo, Rio Grande do Sul, jun. 2014

ZORDAN, S. E. Entulho da indústria da Construção Civil. São Paulo: PCC; EPUSP, 2002. Disponível em: <www.reciclagem.pcc.usp.br/entulho_ind_ccivil. htm> Acesso em: 11 jul. 2017. 